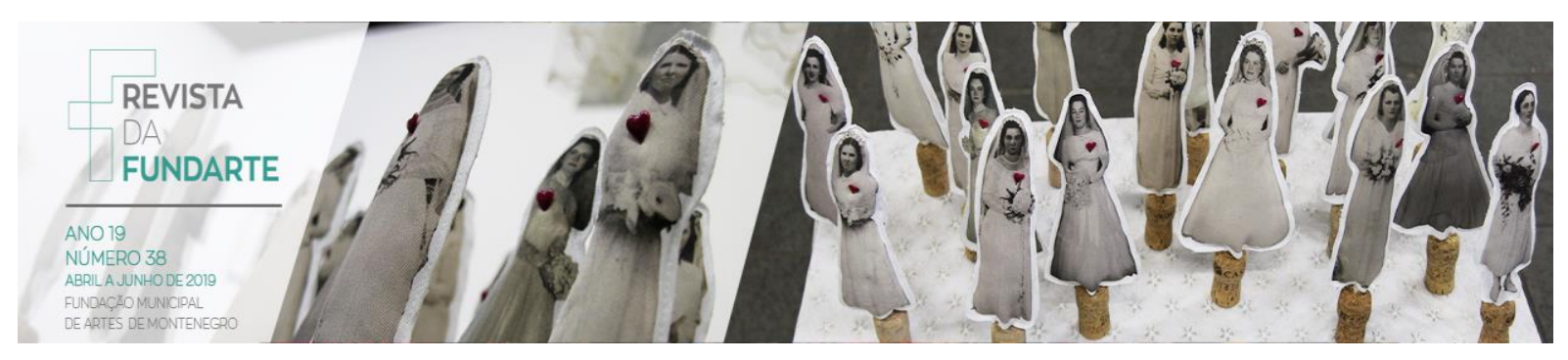

\title{
DESCOLONIZANDO A EDUCAÇÃO ATRAVÉS DA DANÇA: ESTRATÉGIAS DE COMBATE AO RACISMO EM SALA DE AULA - UERGS ${ }^{1}$
}

\author{
Gabriela Souza da Rosa (Rita Léndé) ${ }^{2}$ \\ Autora \\ Ma. Kátia Salib Deffaci3 \\ Orientadora \\ Ma. Aline da Silva Pinto 4 \\ Orientadora
}

\begin{abstract}
Resumo: O presente relato tem por objetivo dialogar sobre a temática que permeia a lei $10.639 / 03^{5}$, em específico a cultura de matriz africana em sala de aula através da dança. Para trazer então à tona não só a questão do desenvolvimento e trabalho da lei em sala de aula, mas sim, maneiras de sensibilizar, problematizar e de re-educar no sentido de descolonizar a educação para todas as crianças e adolescentes, através das danças de expressões negras brasileiras e contemporâneas sobre outros olhares tornando sua prática uma vivência de sensibilização, consciência, e humanização de si enquanto indivíduo e em suas relações com o coletivo.
\end{abstract}

Palavras Chave: Educação; Dança; 10.639/03

\footnotetext{
1 Nota do Editor: Este Relato de Experiência foi apresentado no $26^{\circ}$ Seminário Nacional de Arte e Educação da FUNDARTE que ocorreu de 1 a 3 de outubro de 2018.

2 Gabriela Souza da Rosa (nome social Rita Rosa), possui formação se pelo Grupo Experimental de Dança da Cidade de Porto Alegre na turma de 2013. Graduanda em Dança: Licenciatura, pela Universidade Estadual do Rio Grande do Sul (UERGS). Participou e participa ativamente de grupos renomados de pesquisa sobre a cultura de matriz africana e afro-brasileira. Produz e organiza 0 SEMINÁRIO DE DANÇA AFRO DO RIO GRANDE DO SUL. Diretora, dramaturga e dançarina da montagem solo Id.Percursos. Atua em coletivos e projetos de pesquisa, performance, teatro e dança contemporânea. Pesquisadora da dança e de processos criativos da arte e performances negra contemporânea.

3 É professora assistente da Graduação em Dança: Licenciatura da Universidade Estadual do Rio Grande do Sul/UERGS e líder do Grupo de Pesquisa CORPOETICA - Poéticas do Corpo/UERGS. Cursando Doutorado em Educação na Universidade Estadual de Campinas/UNICAMP. É bacharel e licenciada em Dança pela Universidade Estadual de Campinas/UNICAMP e Mestra em Artes Cênicas pelo Programa de Pós Graduação em Artes Cênicas da Universidade Federal do Rio Grande do Sul/UFRGS. Pesquisa dança, educação somática, educação infantil e cultura popular brasileira. Tem experiência na área de Arte, com ênfase em Execução da Dança, atuando principalmente nos seguintes temas: corpo, processos de criação, criança.

${ }^{4}$ Formação em Licenciatura Plena em Educação Física/ IPA-RS (1999)Especialista em Educação Psicomotora/ FAPA-RS (2001), Mestre em Educação/ Unilasalle-RS (2010), Doutoranda em Diversidade Cultural e Inclusão Social / Universidade Feevale. Atualmente atua como docente do curso de Educação Física da Universidade Feevale e do Curso de Graduação em Dança: Licenciatura, da Universidade Estadual do Rio Grande do Sul. Pesquisadora da área de Corpo e Envelhecimento. Participante do grupo de pesquisa: Poéticas do corpo -UERGS.

${ }^{5}$ Lei que prevê o ensino da História e Culturas Afro Brasileiras e Africanas nas escolas de todo o País.
}

ROSA, Gabriela Souza da(Rita Léndé); DEFFACI, Kátia Salib; PINTO, Aline da Silva. Descolonizando a Educação através da Dança: estratégias de combate ao racismo em sala de aula - UERGS.

Revista da FUNDARTE, Montenegro, p.219-225, ano 19, oㅡ 38, abril/junho de 2019.

Disponível em: http://.seer.fundarte.rs.gov.br/index.php/RevistadaFundarte/index> 28 de junho de 2019 


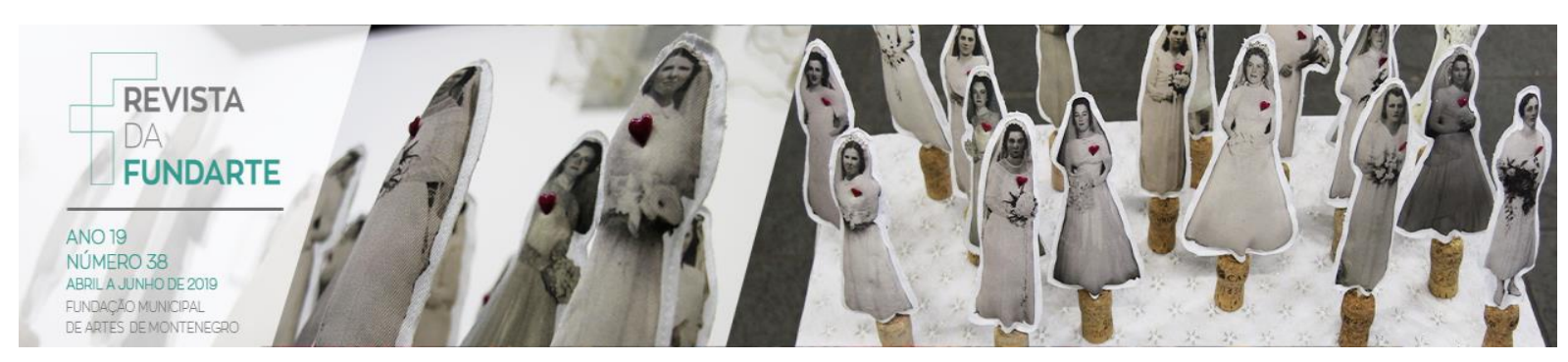

\title{
DESCOLONIZANDO EDUCATION THROUGH DANCE: STRATEGIES TO COMBAT RACISM IN THE CLASSROOM-UERGS
}

\begin{abstract}
The present report aims to discuss the theme that permeates the law $10,639 / 03$, in particular the culture of African array in the classroom through dance. To bring to the fore not only the issue of development and law enforcement work in the classroom, but rather, ways to raise awareness, discuss and educate in order to decolonize the education for all children and adolescents, through the dances of expressions Brazilian and contemporary black on other perspectives making your practice an experience of awareness, consciousness, and humanization of oneself as an individual and in their relations with the collective.
\end{abstract}

Keywords: Education; Dance; 10.639/03

\section{$\underline{\text { Relato de Experiência }}$}

Descrevo a experiência de um período de aulas de Dança em uma Escola Estadual de Ensino Médio no município de Montenegro/RS, durante o Estágio Supervisionado em Arte da Graduação em Dança Licenciatura pela Universidade Estadual do Rio Grande do Sul.

Meu primeiro dia de estágio tinha como intenção uma apresentação formal minha, dos meus alunos e do conteúdo que iria abarcar estava baseado na lei 10.639/03. Apresentei meus 3 nomes ${ }^{16}$ para eles: o de registro, o artístico e o religioso em que esse último afirmou meu lugar de fala como mulher negra do Culto de Matriz Africana. A partir desse momento expus o conteúdo no quadro, explanando que as aulas seriam fundamentadas na lei 10.639/03 e que tal lei tinha a intenção de combater o racismo e produzir reparação histórica baseado nos Valores Civilizatórios Africanos no Brasil. Procurei relacionar tais valores tanto para as aulas de Dança quanto para as aulas expositivas. Depois da exposição, fiz a chamada para conhecer os alunos e suas expectativas sobre as aulas do meu estágio, posteriormente minha apresentação, buscando, também, saber quem e quantos seriam os alunos que iriam participar das aulas práticas de Dança. Eram 6 alunos e 12 alunas, entre 16 e 19 anos de idade, formando um total de 18 alunos, sendo 6 negros/mestiços e 2(dois) alunos do programa Bolsa Família nesse total. Desses 18

\footnotetext{
${ }^{6}$ Gabriela Souza da Rosa (nome de adoção), Rita de Cássia Mesquita da Rosa (nome de registro biológico) e Obà Léndé ( Orukó, nome de batismo no culto afro religioso).
}

ROSA, Gabriela Souza da(Rita Léndé); DEFFACI, Kátia Salib; PINTO, Aline da Silva. Descolonizando a Educação através da Dança: estratégias de combate ao racismo em sala de aula - UERGS.

Revista da FUNDARTE, Montenegro, p.219-225, ano 19, № 38, abril/junho de 2019.

Disponível em: http://.seer.fundarte.rs.gov.br/index.php/RevistadaFundarte/index> 28 de junho de 2019 


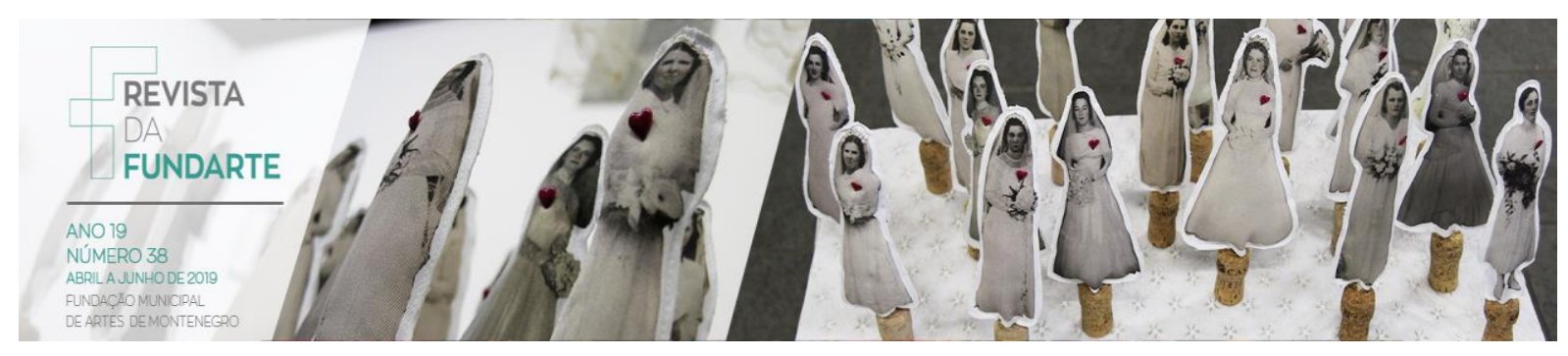

alunos (dada a exposição para realização da chamada e expectativa dos alunos) 10 se interessaram pelas aulas práticas, porém do total desse grupo somente 7 participavam de fato das atividades, onde do total de toda a turma 5 eram evangélicos e não sentiam interesse em Dançar por conta de sua religião, e 4 não tinham interesse pelas aulas práticas por alegarem não saber dançar. Conforme as aulas foram passando e as aulas foram acontecendo, procurava sempre de alguma maneira elencar conceitos sobre a negritude de maneira expositiva através da dança. A maior dificuldade em sala de aula de fato, foi a falta de tempo que tive com os alunos. Do total de 10 encontros para trabalhar com o conteúdo que programei do estágio, onde os esses encontros ocorriam 1 vez por semana com o tempo de $1 \mathrm{~h} 30 \mathrm{~m}$ por aula com intervalo (recreio) de 15 minutos, não houve tempo hábil para trabalhar de maneira proveitosa com todo o conteúdo que havia preparado. E não só a falta de tempo, mas também, a greve e feriados que houveram em meio ao estágio, que acabou interrompendo o conteúdo. Por vezes me senti cansada pela falta presente dos alunos e principalmente pela falta de interesse dos mesmos em trabalhar com assuntos relacionados às relações-étnico raciais. Por eles mesmos dizerem que eram assuntos que eram desnecessários e que mesmo sendo brancos também sofriam com o racismo. Goulart (2016) aborda o espelhamento existente dos alunos da periferia que se vêem diante da própria realidade abordada pelo professor o que faz com que neguem a própria realidade buscando constantemente falar e viver sobre uma vida que ou os invibiliza ou os massacra preferindo negar o que vê diante do espelhamento causado pelo(a) professor, por fim aceita a realidade de falsas facilidades. Encontrei-me diante dessa realidade na $4^{2}$ (quarta) aula, durante o questionamento sobre onde estavam as pessoas negras nos espaços que comumente freqüentavam, a partir do Teste do Pescoço $^{7}$ (GELEDÉS, 2014), como por exemplo: shoppings centers, redes grandes de supermercados existentes no

\footnotetext{
${ }^{7}$ Teste que trazer a atenção do olhar para o cotidiano, procurando localizar onde estão os negros em todos os ambientes de nossa esfera social, cultural e política, procurando perceber a partir disso qual lugar que é posto o sujeito negro na sociedade brasileira, evidenciando o racismo e por fim a diferença de classes.
}

ROSA, Gabriela Souza da(Rita Léndé); DEFFACI, Kátia Salib; PINTO, Aline da Silva. Descolonizando a Educação através da Dança: estratégias de combate ao racismo em sala de aula - UERGS.

Revista da FUNDARTE, Montenegro, p.219-225, ano 19, no 38, abril/junho de 2019.

Disponível em: http://.seer.fundarte.rs.gov.br/index.php/RevistadaFundarte/index $>28$ de junho de 2019 


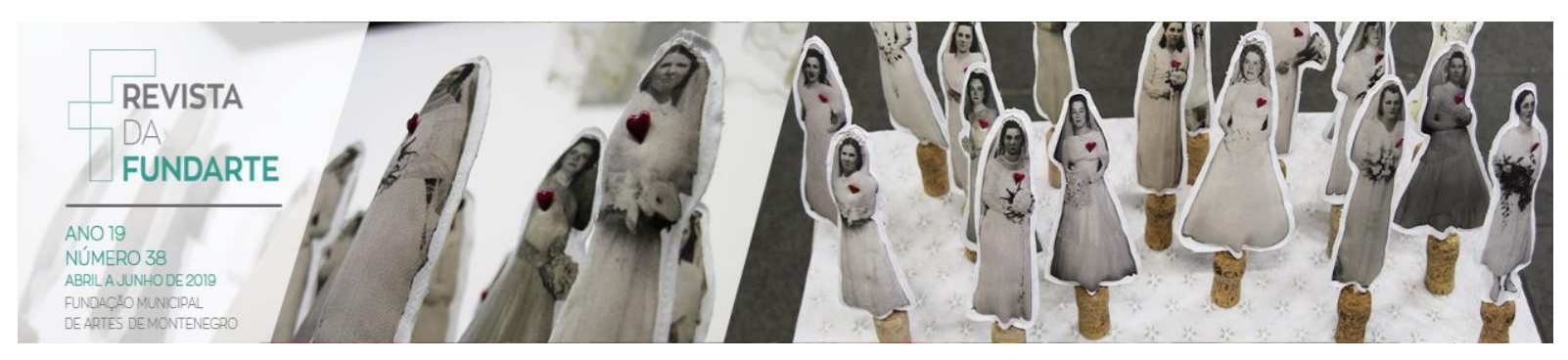

município, vídeos clips de suas bandas prediletas, novelas, programas televisivos de entretenimento dominical que continham bailarinas/dançarinas/animadoras de públicos, programas de humor, na escola e na própria sala de aula. Com essas questões em exemplo perguntei para a turma onde estavam, então, os corpos negros na Dança, principalmente de mulheres negras, e conheciam alguém que tenha se destacado e se dado bem nessa área, a partir dessa análise. Ouvi como resposta o discurso da Meritocracia, tanto alunos negros como brancos, alengando que estavam nos subempregos por escolha própria. Então levantei outra questão: pois já que estavam por escolha e vontade própria na escola, o que faltava então para abrir o olhar para essa realidade? Porque não a transformam? Já que muitos se viam nesses espaços, alegando serem privilegiados: esse privilégio vem de onde? Como foi construído? Como fazemos para reconhecer a cultura daqueles que não são vistos? Como a gente dança então a Cultura daquele que é invisível? Esta aula foi um marco de tensionamentos, silenciamentos e negações. A partir desse dia houveram mais 6 aulas, porém foi necessário juntar duas aulas em um encontro de uma hora e meia por conta de um feriado e paralisação geral dos caminhoneiros. Tivemos mais 4 encontros, onde desses 4 , duas aulas foram práticas, uma com vídeo, outra expositiva e outra de avaliação. Finalizar os encontros foi de uma infelicidade inexplicável, pois nesse período de estágio fui atravessada por uma série de aspectos relacionados ao tempo, que se necessita para trabalhar com temáticas tão profundas e densas, principalmente quando localizadas no corpo, ainda mais quando transversalizadas à margem existente sobre a cultura negra de matriz africana. Encontrei algo que não findava no estágio, sai com algo ainda por ser trabalhado, ainda por ser humanizado, ainda por ser continuado, saí em estado de abandono, sobre um hiato que permaneceu e soube dar conta. Parafraseando Gilberto Gil $^{8}$ o tempo ele é rei e diz espera. Por conta disso me surgiu uma citação onde Paulo Freire diz:

${ }^{8}$ Cantor Nacionalmente conhecido na Música Popular Brasileira: Tempo Rei.

ROSA, Gabriela Souza da(Rita Léndé); DEFFACI, Kátia Salib; PINTO, Aline da Silva. Descolonizando a Educação através da Dança: estratégias de combate ao racismo em sala de aula - UERGS.

Revista da FUNDARTE, Montenegro, p.219-225, ano 19, no 38, abril/junho de 2019.

Disponível em: http://.seer.fundarte.rs.gov.br/index.php/RevistadaFundarte/index> 28 de junho de 2019 


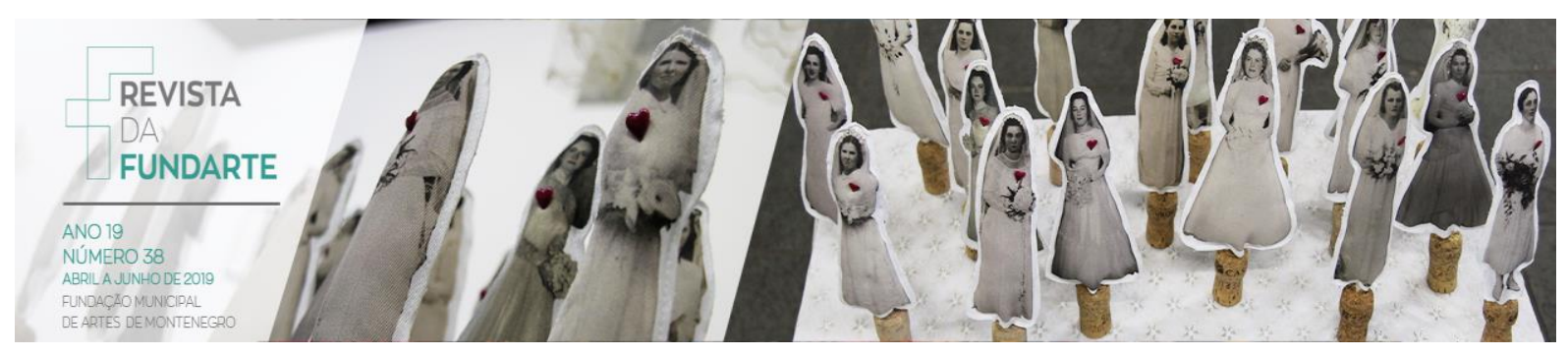

Como professor não devo poupar oportunidade para testemunhar aos alunos a segurança com que me comporto ao discutir um tema, ao analisar um fato, ao expor minha posição em face de uma decisão governamental. Minha segurança não repousa na falsa suposição de que sei tudo, de que sou o "maior". Minha segurança se alicerça no saber confirmado pela própria experiência de que, se minha conclusão, de que sou consciente, atesta, de um lado, minha ignorância, me abre, de outro, o caminho para conhecer. [...] A experiência da abertura como experiência fundante do ser inacabado que terminou por se saber inacabado. Seria impossível saber se inacabado e não se abrir para o mundo e aos outros à procura de explicação, de respostas a múltiplas perguntas. O fechamento ao mundo e aos outros se torna transgressão ao impulso natural da incompletude.

O sujeito que se abre ao mundo e aos outros inaugura com seu gesto a relação dialógica em que se confirma como inquietação e curiosidade, como inconclusão em permanente movimento na história. (FREIRE, 2013, p. 132, 133).

Os encontros do estágio não tinham como ideal falar somente em dança e praticar a dança, não tinham o intuito de pejorar ainda mais uma cultura que já vista a olhos da folclorização sobre o gesto da cultura negra de Matriz Africana. Jogando-a no banal senso comum por segundo plano. Abordar a Dança com recorte de cultura e raça, é afirmar um lugar de fala, é se apresentar de maneira específica. A fala traz uma visão de mundo amplamente banalizada, coisificada, endemonizada quando no sentido dos cultos de religiões africanas. O meu corpo não só carrega a cor, carrega o gênero atrelado a uma religiosidade imbuída de valores civilizatórios, logo, esse corpo é uma imagem só. A partir da interlocução de si, é vista com o pano do preconceito que encobre todos esses estigmas sociais. É a visão clara e lúcida de uma boca que fala atrelada a um corpo que traz tensionamento. Depois das apresentações a introdução do conteúdo, falar sobre uma obrigação que existe em lei, explicar a lei 10.639/03 de maneira clara, direta e específica. E essa fala COMO docente, essa apresentação se dará de maneira fundamentada através da lei 10.639/03. Tal lei versa sobre os Valores Civilizatórios Afro Brasileiros. Esses valores visam falar de humanização, de consciência que na prática se dá maneira direta à relação de afeto e amorosidade, através de um olhar sensível e não endemonizado sobre a cultura negra.

ROSA, Gabriela Souza da(Rita Léndé); DEFFACI, Kátia Salib; PINTO, Aline da Silva. Descolonizando a Educação através da Dança: estratégias de combate ao racismo em sala de aula - UERGS.

Revista da FUNDARTE, Montenegro, p.219-225, ano 19, no 38, abril/junho de 2019.

Disponível em: http://.seer.fundarte.rs.gov.br/index.php/RevistadaFundarte/index> 28 de junho de 2019 


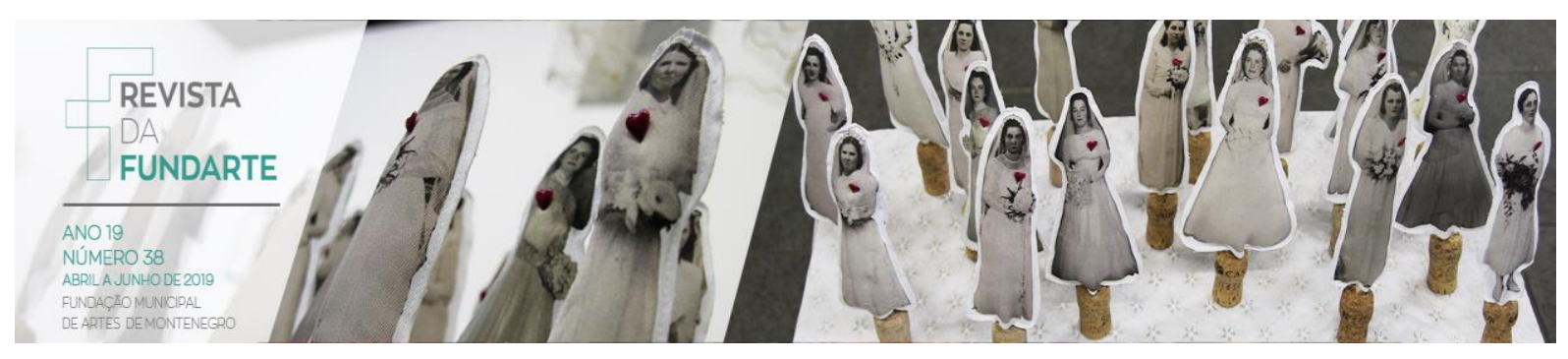

É nosso papel enquanto educadores, compreender como os diferentes povos, ao longo da história, classificam a si mesmos e aos outros, como certas classificações foram hierarquizadas no contexto do racismo e como este fenômeno interfere na construção de uma escola democrática. E também tarefa do educador e da educadora entender o conjunto de representações sobre o negro existente na sociedade e na escola, e enfatizar as representações positivas construídas politicamente pelos movimentos negros e pela comunidade negra. (GOMES, 2003 p.77).

O desafio, então, é desenvolver a valoração da prática e teoria em Dança permeada nas expressões da Cultura Negra da diáspora brasileira em sala de aula no Ensino Médio. Esse desafio dialoga com os Valores Civilizatórios Afro Brasileiros Africanos e Indígenas pela lei 10.639/03, antecessora Da lei 11.645/08, em que tais leis visam o ensino de História e Cultura Afro Brasileira e Indígena na sala de aula. Para procurar lacunas ou lugares para desenvolver outros pontos de vista sobre a história e cultura negra, dada a atual diversidade étnica e cultural existente em nosso país. Com a consciência elencada sobre nossos processos sociais com base na cultura atual do processo estratégico da educação, com base na higienização e apagamento histórico através do genocídio.

\section{Referencias:}

FREIRE, Paulo. Pedagogia da Autonomia: saberes necessários à prática educativaRio de Janeiro: Paz e Terra, 2013.

GOMES, Nilma Lino. Educação e Identidade Negra. Universidade Federal de Minas Gerais, Aletria, Minas Gerais, 2002.

GOULART, Treyce Hellen Silva. Narrativas Entrecruzadas De Professoras Negras: Trajetórias, Pactos Políticos e Prática Docente. Universidade Federal do Rio Grande, Programa de Pós Graduação em Educação (FURG- PPGEDU), 2016.

Modos de brincar: caderno de atividades, saberes e fazeres / [organização Ana Paula Brandão, Azoilda Loretto da Trindade]. - Rio de Janeiro: Fundação Roberto Marinho, 2010. (A cor da cultura ; v.5)

SITE:https://www.geledes.org.br/existe-racismo-brasil-faca-o-teste-pescoco-edescubra/

ROSA, Gabriela Souza da(Rita Léndé); DEFFACI, Kátia Salib; PINTO, Aline da Silva. Descolonizando a Educação através da Dança: estratégias de combate ao racismo em sala de aula - UERGS.

Revista da FUNDARTE, Montenegro, p.219-225, ano 19, no 38, abril/junho de 2019.

Disponível em: http://.seer.fundarte.rs.gov.br/index.php/RevistadaFundarte/index> 28 de junho de 2019 